\title{
Anti-diabetic, haematinic and anti-cholesterolmic effects of carrot (Daucus carota Linn.) juice metabolites to cure alloxan monohydrate induced type-I diabetes in albino rats
}

\begin{abstract}
Introduction: In present study an effort has been made to assess the hypoglycemic, Anticholestrolemic and haematinic activity of carrot juice in alloxan monohydrate induced experimental animal model.

Materials and methods: Rats were acclimatized for 7 days in lab temperature. All animals were given standard water and pellet diet. Diabetes was induced in rats with the help of alloxan monohydrate $(140 \mathrm{mg} / \mathrm{kg}$ body weight). After alloxan monohydrate injection rats were separated and treatment started with carrot juice and insulin.

Results and discussion: A marked rise in fasting blood glucose as well as serum cholesterol level was observed in diabetic control rats when compared to normal control rats. Antihyperglycemic, Anti-cholesterolmic and haematinic activity observed in carrot juice administered rats on 7 th, 14 th, 21 st and 28 th days post treatment. Anti-hyperglycemic and anti-cholesterol mic activity was found less effective than that of insulin treatment group.

Conclusion: It is hope that present investigation will be helpful in establishing a scientific basis for antidiabetic, haematinic and Anti-cholesterolmic effects in experimental animal

model. The results are $(<0.001)$ statistically significant.
\end{abstract}

Volume 7 Issue I - 2020

\author{
Sanjeev Kumar,' Kumari Shachi, ${ }^{2}$ Nayan \\ Kumar Prasad, ${ }^{3}$ NK Dubey, ${ }^{4}$ Usha Dubey ${ }^{5}$ \\ 'Dept of Zoology, B.M.College, Rahika (L. N. Mithila University \\ Darbhanga), India \\ ${ }^{2}$ Dept of Zoology, K.S.College Laheriasarai (L.N.Mithila \\ University Darbhanga), India \\ ${ }^{3}$ Dept of Zoology, Tribhuvan University, RRM Campus, Nepal \\ ${ }^{4}$ Retd Prof. University Dept of Zoology, L.N.Mithila University, \\ India \\ ${ }^{5}$ Head Dept of zoology, NJM College, Laheriasarai (L.N.Mithila \\ University Darbhanga) India
}

Correspondence: Kumari Shachi, Dept of Zoology, K.S.College Laheriasarai (L.N.Mithila University Darbhanga), India, Email shachi.lucky7@gmail.com

Received: April 06, 2020 | Published: May II, 2020

Keywords: daucus carota, diabetes, blood glucose, insulin, anti-cholesterolmic

\section{Introduction}

Diabetes mellitus is an endocrine alteration of multiple pathologies (like cardiomyopathy, nephropathy, retinopathy, neuropathy, angiopathy etc.) caused by elevated blood glucose. Increased blood glucose causes defects of carbohydrate, protein and lipid metabolism. Recently India has undergone rapid urbanization and industrialization resulting into remarkable changes in the life style and food habit Most urban people lead a static life, consume tobacco and take high calorie diet Kumar S et al., ${ }^{1}$ Inspite of tremendous advancement in the field of allopathic medical sciences, incidence of diabetes mellitus is continuously increasing due to consuming high calorie diet with lack holistic life style approaches. Incidence of type-2 as well as type-1 diabetes increasing globally at war foot levels. During the year 2020, India had 31.7 million people suffering from suffering from diabetes mellitus (IDDM and NIDDM) and after eleven years total number of diabetes has double to 62.4 million. Several oral and injectable anti-diabetic drugs are used in treatment of diabetes. The existing group of oral hypoglycemic drugs includes sulphonylureas, biguanide alpha-glucosidase inhibitor, glucagon like peptide analogs, dipeptidyl peptidase-4 inhibitors, PPAR-y agonist etc are in use. Recently SGLT 2 inhibitors (in kidney), aldolase reductase inhibitors, agonists of fibroblast growth factors-21(FGF-21) are being explored. Several side effects associated with the use of such oral or injectable hypoglycemic agents during or after treatment have been reported Samantha et al., ${ }^{2}$ Monami et al., ${ }^{3}$ But no any side effect associated with the use of herbal drugs Sarvanan \& Leelavinothan. ${ }^{4}$ There is growing interest in herbal remedies for diabetes, due to their availability and lesser side effects.
Gradually increasing order of this disease effect the society, for those medical sciences is busy to search some positive technology by which this abnormality can be deleted Kumar et al., ${ }^{5}$ IDDM and NIDDM both form of diabetes have very serious effect on the health. In last few years there has been an exponential growth in the field of herbal medicine. These drugs are gaining popularity both in developing and developed countries because of their natural origin and less side effects. Many traditional medicines in use are derived from medicinal plants, minerals and organic matter.

A number of medicinal plants traditionally used for over 1000 years named rasayana and present in herbal preparations of Indian traditional health care system. In Indian system of medicine most practiced formulate their own treatment. The WHO has listed 21,000 plants, which are used for medicinal purposes around the world. Among these 2500 species are in India, out of which 150 species are used commercially on fairly large scale. India is the largest producer of Medicinal herbs. ${ }^{6}$ A number of clinical studies have been carried out in recent years that show potential links between herbal therapies and improved blood glucose levels. Medicinal plant based industries in developing countries lack information on the social and economic benefits that could be derived from industrializing utilization of medicinal plants. Plants are being used as food, vegetables, cosmetic and medicinal purposes. Medicinal plants have a great role in treatment of various diseases. An example of such plant is carrot (Daucus carota Linn.) that belongs to umbellifer family Apiaceae. Carrot reduce the blood glucose and cholesterol Abbey et al., ${ }^{7}$ Majumdar et al., ${ }^{8}$ Nicolle et al., ${ }^{9}$ Wisker et al., ${ }^{10}$ and anti-oxidant, appetizer, removing gall 
bladder stone, spectorant and bronchodilator Abbey et al., ${ }^{7}$ Present investigation was conducted to evaluate the anti-diabetic, anticholesterolmic and haematinic properties in alloxan monohydrate administered animal model.

\section{Materials and methods}

Plant materials: The carrot juice used for present investigation. It was obtained from the vegetable market of Darbhanga, India.

Juice of carrot: Firstly, Carrot was cleaned and the juice was extracted. Male albino rats (200-220gm and 10-12 weeks) were used as experimental animals. Animals were procured from local supplier of Darbhanga, India. The rats were acclimatized for 7 days. All the animals were fed with rodent pellet diet. Water was allowed adlibitum under strict hygienic condition.

Induction of diabetes: Alloxan Monohydrate is a toxic glucose analogue which selectively destroys insulin producing cell in pancreas. This cause's insulin dependent diabetes mellitus called "Alloxan Diabetes" Lenzen. ${ }^{11}$ Alloxan monohydrate was obtained from Explicit Chemicals Pvt.Ltd, Pune, India.

\section{Experimental design:}

1. Normal Control

2. Diabetic control

3. Alloxan+Carrot Juice treatment

\section{Alloxan+Insulin treatment}

The diabetes was induced in 12 hours fasted animal by a single intraperitoneal injection of freshly prepared solution of Alloxan monohydrate $(140 \mathrm{mg} / \mathrm{kg}$ body weight) in $0.5 \mathrm{ml}$ normal saline water. After 72 hours of Alloxan monohydrate injection, the diabetic rats (blood glucose levels $<280 \mathrm{mg} / \mathrm{dl})(>280$ not $<280)$ were separated. Treatment was started except in normal control and diabetic control animals. During further investigation all experimental group animals were given standared hygienic water and pellet diet.

\section{Results and discussion}

A significant rise in fasting blood glucose levels was recorded in diabetic control when compared to normal control rats. Antidiabetic, anti-cholesterolmic and haematinic activity was recorded in carrot juice treated rats on $7 \mathrm{th}, 14 \mathrm{th}, 21 \mathrm{st}$ and 28 th day post treatment. The haemoglobin concentration of untreated diabetic rat was also lower than that of the other groups. The serum cholesterol of diabetic control animals was higher than other experimental group. Anti-cholesterolmic activities were recorded in juice and insulin administered animals. Oral glucose tolerance test was significantly improved in juice treated animals compared to diabetic control group. The results are shown in Tables 1-4. Carrot juice was found less effective than that of the insulin treatment group. The result of the present investigation indicate that carrot juice have the property to lowers the blood glucose levels. Alloxan monohydrate facilitates the production of free radicals and causes the tissue damage. The beta cells of pancreas are susceptible to such damage. It appeares Kumar et al., ${ }^{1}$ has also reported that beet root juice treated rats showed reduction of blood glucose in alloxan monohydrate induced diabetic rats. Finding in this regard with carrot juice and beet root juice were also no different. Khayatnouri $\mathrm{M}$ et al., ${ }^{12}$ have also observed reduction in blood glucose levels and cholesterol with administration of carrot juice in streptozotocin induced diabetic male mice. Findings in the present study too are in accordance with the findings discussed above carrot juice has been widely used for curing various maladies. Present investigation will be helpful in establishing a scientific basis for antidiabetic, anti-cholesteromic and haematinic uses of Carrot juice in alloxan induced experimental animal model. Carrot juice tolerated the overdose of glucose through oral glucose tolerance test in juice treated experimental animals. However, much more studies are still required to explore the other potential of this root juice.

Table I Anti diabetic effect of carrot juice and insulin in experimental animals

\begin{tabular}{|c|c|c|c|c|}
\hline \multirow[b]{2}{*}{ Experimental Design } & \multicolumn{4}{|c|}{ Fasting blood glucose Level (mg/dl) } \\
\hline & 7th day & I4th day & 2 Ist day & 28th day \\
\hline Normal Control & $90.22 \pm 1.84$ & $88.72 \pm 1.32$ & $90.66 \pm 1.23$ & $90.62 \pm 1.83$ \\
\hline Diabetic Control & $290 \pm 1.84$ & $288 \pm 1.34$ & $298 \pm 1.36$ & $290 \pm 1.63$ \\
\hline Alloxan+Carrot Juice & $280 \pm 2.08$ & $250 \pm 1.34$ & $229 \pm 1.38$ & $136 \pm 1.23$ \\
\hline treatment (1000mg/kg body weight) & $\mathrm{P}<0.00 \mathrm{I}$ & $P<0.001$ & $P<0.001$ & $P<0.001$ \\
\hline Alloxan+Insulin & $264 \pm 7.02$ & $260 \pm 2.64$ & $210 \pm 1.38$ & $132 \pm 3.46$ \\
\hline (Human Mixtard®) & $P<0.001$ & $P<0.001$ & $P<0.001$ & $P<0.001$ \\
\hline
\end{tabular}

Value are Mean \pm S.E.M, $n=6, P<0.00 I$ vs diabetic control

Table 2 Haematinic effect of carrot juice and insulin in experimental animals

\begin{tabular}{|c|c|c|c|c|}
\hline \multirow[b]{2}{*}{ Experimental Design } & \multicolumn{4}{|c|}{ Blood Hemoglobin (g/dl) } \\
\hline & 7th day & I4th day & 2 I st day & 28th day \\
\hline Normal Control & $|5.2 \pm 0.3|$ & $16.6 \pm 0.03$ & $14.7 \pm 0.23$ & $15.3 \pm 0.43$ \\
\hline Diabetic Control & $14.4 \pm 0.30$ & $13.2 \pm 0.69$ & $|2.00 \pm 0.4|$ & $13.3 \pm 0.23$ \\
\hline \multicolumn{5}{|l|}{ Alloxan+Carrot Juice } \\
\hline $\begin{array}{l}\text { treatment }(1000 \mathrm{mg} / \mathrm{kg} \text { body } \\
\text { weight })\end{array}$ & $16.02 \pm 0.43$ & $16.90 \pm 0.43$ & $16.9 \pm 0.32$ & $16.5 \pm 0.36$ \\
\hline Alloxan+Insulin (Human & $|5.2 \pm 0.3|$ & $|5.02 \pm 0.4|$ & $15.60 \pm 0.62$ & $15.23 \pm 0.32$ \\
\hline Mixtard () & & & & \\
\hline
\end{tabular}

Value are Mean \pm S.E.M, $n=8, P<0.001$ vs diabetic control

Citation: Kumar S, Shachi K, Prasad NK, et al.Anti-diabetic, haematinic and anti-cholesterolmic effects of carrot (Daucus carota Linn.) juice metabolites to cure alloxan monohydrate induced type-I diabetes in albino rats.J Diab Metab Disorder Control. 2020;7(I):37-40. DOI: I0.I5406/jdmdc.2020.07.00I97 
Table 3 Effect of carrot juice and insulin on biochemical profile in experimental animals

\begin{tabular}{|c|c|c|c|c|c|c|c|c|}
\hline \multirow{3}{*}{ Experimental Design } & \multicolumn{8}{|c|}{ Biochemical Parameters (mg/dl) } \\
\hline & \multicolumn{2}{|l|}{ 7th day } & \multicolumn{2}{|l|}{ I4th day } & \multicolumn{2}{|l|}{2 Ist day } & \multicolumn{2}{|l|}{ 28th day } \\
\hline & SC & SP & SC & SP & SC & SP & SC & $\mathbf{S P}$ \\
\hline Normal Control & $107 \pm 1.03$ & $1.36 \pm 0.6$ & $108 \pm 2.09$ & $\begin{array}{l}6.39 \\
\pm 0.17\end{array}$ & $109 \pm 1.03$ & $6.23 \pm 0.73$ & $106 \pm 2.68$ & $1.39 \pm 0.37$ \\
\hline Diabetic Control & $182 \pm 2.18$ & $4.69 \pm 0.04$ & $180 \pm 2.83$ & $4.42 \pm 1.09$ & $189 \pm 1.09$ & $4.18 \pm 1.08$ & $188 \pm 1.69$ & $4.43 \pm 2.09$ \\
\hline $\begin{array}{l}\text { Alloxan+Carrot Juice } \\
\text { treatment }(1000 \mathrm{mg} / \mathrm{kg} \text { body weight })\end{array}$ & $126 \pm 0.46$ & $5.07 \pm 0.64$ & $126 \pm 0.63$ & $6.02 \pm 0.49$ & $122 \pm 0.75$ & $5.06 \pm 6.69$ & $121 \pm 1.18$ & $5.91 \pm 6.23$ \\
\hline Alloxan+Insulin (Human Mixtard®) & $123 \pm 0.48$ & $6.06 \pm 0.89$ & $122 \pm 0.93$ & $6.03 \pm 0.83$ & $118 \pm 0.23$ & $6.23 \pm 0.19$ & $118 \pm 2.19$ & $6.23 \pm 2.13$ \\
\hline
\end{tabular}

SC, serum cholesterol; SP, serum protein

Value are mean $\pm S E M, n=6, p<0.00 I$ vs diabetic control

Table 4 Effect of oral glucose tolerance test (OGTT) in experimental animals

\begin{tabular}{|c|c|c|c|c|}
\hline \multirow[b]{2}{*}{ Experimental Design } & \multicolumn{4}{|c|}{ Blood glucose levels (mg/dl) } \\
\hline & 30 minutes & 60 minutes & 90 minutes & I 20 minutes \\
\hline Normal Control & $|80 \pm 5.2 .0|$ & $165 \pm 1.08$ & $120.20 \pm 4.60$ & $96.40 \pm 1.10$ \\
\hline Diabetic Control & $339 \pm 5.2 .60$ & $366 \pm 2.20$ & $346 . \pm 1.12$ & $330.40 \pm 3.30$ \\
\hline Alloxan+Carrot Juice treatment & $200.28 \pm 214$ & $136.18 \pm 6.12$ & $136.18 \pm 2.68$ & $140.30 \pm 4.60$ \\
\hline (1000mg/kg body weight) & $P<0.00$ I & $P<0.001$ & $P<0.001$ & $P<0.001$ \\
\hline Alloxan+Insulin & $250.26 \pm 4.12$ & $206.18 \pm 3.18$ & $126 \pm 2.12$ & $119.7 \pm 3.19$ \\
\hline (Human Mixtard®) & $P<0.001$ & $\mathrm{P}<0.00 \mathrm{I}$ & $P<0.001$ & $P<0.001$ \\
\hline
\end{tabular}

Value are Mean \pm S.E.M, $n=8, P<0.00 I$ vs diabetic control

\section{Conclusion}

Western lifestyle is on sharp rise in India and also is the rise and prevalence of diabetes. The cost of treatment is already running many families in ruler India. This research appears that carrot juice works as anti-diabetic as well as haematinic agent. We got the positive effects of carrot juce on experimental diabetic animals. So this root will be helpful in treating the diabetes in ruler India due to low cost, easily availability and lesser side effects associated with the use of this plant root. The treatment of diabetic patient with carrot juice will be more beneficial than allopathic treatments.

\section{Acknowledgments}

The authors are thankful to Head, University Department of Zoology, L.N.Mithila University Darbhanga, India for the lab facilities provided. The authors are also thankful to Mr. Dinesh Munot Explicit Chemical Pvt.Ltd. Pune for providing free sample of Alloxan monohydrate for the present investigation.

\section{Conflicts of interest}

The authors declare no conflict of interest.

\section{Funding}

None.

\section{References}

1. Kumar S, Shachi K. Therapeutic efficacy of Azadirachta indica leaves in alloxan monohydrate induced type-1 diabetes in albino rats. EC Diabetes and Metabolic Research. 2020;4(2):1-4.

2. Samantha LB, Submit BM, Paul V, et al. Increased cancer related mortality for patients with type-2 diabetes who use sulphonylureas or insulin. Diabetes Care. 2006;29(2):254-258

3. Monami M, Lamanna C, Balzi D, et al. Sulphonylures and cancer a casecontrol study. Acta Diabetol. 2009;46(4):279-284.

4. Sarvanan G, Leelavinothan P. Effects of syzygium cumini bark on blood glucose, plasma insulin and C-peptide in streptozotocin induced diabetic rats. Int J Endocrinol Metab. 2006;4(2):96-105.

5. Kumar S, Shachi K, NK Dubey, et al. Anti-diabetic and haematinic effects of beet root juice (Beta vulgaris L.) in alloxan induced type-1 diabetic albino rats. J Diab Res Ther. 2020;6(1):1-3.

6. Hänninen O, Rauma AL, Kaartinen K, et al. Vegan diet in physiological health promotion. Acta Physiol Hung. 1999;86(3-4):171-180.

7. Abbey M, Noakes M, Nestel PJ. Dietary supplementation with orange and carrot juice in cigarette smokers lowers oxidation products in copperoxidized low-density lipoproteins. J Am Diet Assoc. 1995;95(6):671-675.

8. Majumder PK, Dasgupta S, Mukhopadhaya RK, et al. Anti-steroidogenic activity of the petroleum ether extract and fraction 5 (fatty acids) of carrot (Daucus carota L.) seeds in mouse ovary. J Ethnopharmacol. 1997;57(3):209-212. 
9. Nicolle C, Cardinault N, Aprikian O, et al. Effect of carrot intake on cholesterol metabolism and on antioxidant status in cholesterol fed rat. Eur J Nutr. 2003;42(5):254-261.

10. Wisker E, Schweizer TF, Daniel M, et al. Fibre-mediated physiological effects of raw and processed carrots in humans. BrJNutr. 1994;72(4):579599
11. Lenzen S. The mechanisms of alloxan and streptozotocin induced diabetes. Diabetologia. 2008;51(2):216-226.

12. Khayatnouri M, Nikmanesh M, Safarmashaei S. Study of the effect of gliclazide and carrot juice on blood sugar level in STZ-Z induced diabetic male mice. Advances in Environmental Biology. 2011;5(7):1742-1745. 